\title{
Studies on Exploration of Red Yeast Rice Powder as a Colorant in Ice-Cream and Sweetened Milk
}

\author{
D. D. Toshniwal", H. W. Deshpande, S. D. Katke and A. R. Sawate \\ Department of Food Microbiology and Safety, College of Food Technology, \\ VNMKV, Parbhani, Maharashtra, India \\ *Corresponding author
}

\section{A B S T R A C T}

\section{Keywords}

Red yeast rice, Sweetened milk, Ice-cream, Bio colorant, Monascus purpureus

\section{Article Info}

Accepted:

15 August 2020 Available Online: 10 September 2020
The present study was carried out to determine acceptability of Red Yeast Rice Powder as a colorant. On the basis of findings, it was concluded that the products prepared by using Red Yeast Rice powder as a colorant could be considered as the best from both nutritional and sensory point of view. The Red Yeast Rice powder at the ratio of 1.0 percent was good in terms of color, texture and appearance. The prepared Red yeast Rice powder was stable at room temperature for 90 days when properly packed in suitable packaging material. The fact that it is cheap than the ones which are being sold in market.

\section{Introduction}

Rice (Oryza sativa L.) is known to be a principal food crop of south and south eastern Countries. It is important food for over more than Thirty percent of India's population, thus holds the key role in food security and plays a very important role in financial setup of national economy. The demand for rice is predicted to grow continuously as population is continuously growing. The rice plant belongs to the monocot genus Oryza of Poaceae family. The monocot genus Oryza includes 24 species, of which only two species are widely cultivated like, Oryza sativa and Oryza glaberrima, are cultivable and the rest 22 species are wild. Rice varieties i.e. sativa is further divided into three subspecies that are, japonica, indica, and javanica. India is that producer of rice varieties which belongs to the subspecies indica Department of Rural Development (DRD 2014). Rice is an annual plant which usually grows to a height of about $0.5-2 \mathrm{~m}$ (Gulshan Mahajan et al., 2017).

The word "nutraceutical" and its definition were stated by Stephen DeFelice in year 
1989, from the Foundation for Innovation in Medicine (Founder and Chairman), and it recognizes a food or a part of a food, which is of vegetal or animal origin, and features a pharmaceutical activity (DeFelice, 1995). Red yeast rice (RYR) could be a nutraceutical made by fermentation of polished rice with the mold Monascus purpureus and other related species of molds. Red Yeast Rice (RYR) contains various compounds like polyketides, pigments, monacolins, unsaturated fatty acids, and phytosterols.

Red Yeast Rice (RYR) has been used as an herbal supplement and in the cooking of East Asian countries like China, Japan, and Korea. Red Yeast Rice has been utilized as an herbal additive and in the cooking of food East Asian countries like China, Japan, and Korea. It has been used for flavoring, coloring, and preservation of food and in traditional Chinese medicine for many years (Burke et. al., 2015).

Red Yeast Rice is the fermented product which is produced from normal rice (Oryza sativa) with red mold (Monascus spp.). Red yeast rice is also known with various another name which are ang-kak, hung-chu, hon-chi, hong-gug in Korean, red koji, benikoji, and so on. It has an extended historyas a flavoring, coloring and preservative in food and a folk medicine in many Asian countries. The RYR product is noted to by different names as per the local languages (Woranan and Prasad 2015,). Many species of the mold Monascus have also been widely used in making different products like red wine and red soybean cheese (Chen et. al., 1987). (Hesseltine et al., 1979) The mold Monascus first became known in Western world when van Tieghem (1884) enlisted the use of red powder (red yeast rice) by local populations in Java islands. The fungus that was separated from red mold rice was named Monascus purpureus Went by scientist (Went, 1895), in recognition of the purple color. Today there are more than 30 Monascus strains which are deposited with the American Type Culture Collection (ATCC) or other Institutes like Microbial Type Culture Collection (MTCC), India. Products fermented by Monascus (MFPs) are produced by fermentation process with Monascus species through solid state fermentation or submerged fermentation processes. The common species of Monascus which are usually used for the fermentation are Monascus purpureus, Monascus pilosus, Monascus anka and Monascus ruber. The usual Monascus yielded products which were consumed over the centuries in Asian countries are Red Mold Rice (RMR), is termed as angkak, anka, and red yeast rice.

It has been used from earlier period as food colorant and food preservative, food supplement and in traditional medicine. Scientific studies have confirmed pharmacological effects of Monascus fermentate (Endo et al., 1989) isolated from Monascus purpureus a metabolite, monacolin $\mathrm{K}$, which normalized an artificially induced hyperlipoproteinemia in human trials. The reduced form Mevinolin has been introduced as a cholesterol reducing pharmaceutical. Simple extracts of fermentate lower the HDL cholesterol and triglycerides value in blood (Fink et al., 1989).

Red Yeast Rice Powder (RYR) can be used as a colorant to formulate different food products like Ice-cream, Colored sweetened milk, colored lemon juice, colored buttermilk, etc. which improves appearance whereas, Monacolins and $\mathrm{HmG}$ co-A reductase have shown reduced risk of cardiovascular diseases and promotes health benefits of Red yeast rice. Thus, it is clear that RYR could be successfully value added. Hence, it can be concluded that the RYR is a potential food supplement prepared from solid state rice fermentation which could be in addition to 
daily diet. Red Yeast Rice (RYR) can be implemented on commercial scale. RYR contains many compounds including polyketides, MUFA's, phytosterols, pigments, and monacolins (Patel et al., 2016). Monacolins prohibit activity of enzyme (3hydroxy-3-methylglutaryl- coenzyme A) HMG CoA reductase, which limits cholesterol synthesis. There are at the minimum 13 different monacolin compounds have been isolated from RYR, of which some like monacolin $\mathrm{K}$ is chemically similar to lovastatin, which is a cholesterol-lowering drug (Zhang Z. et al., 2016). Ma, 2000 announced that a red mold rice product traditionally manufactured with Monascus purpureus had a pigment content of $0.3 \%$ in rice flour. Hajjaj et al., (1999) stated that New food applications, like the coloration of processed meats and other meat products (sausage, ham), marine products like fish paste, surimi, tomato ketchup, yoghurt, wine production, flavored milk, and fruit juices or other fruit products were described.

\section{Materials and Methods}

\section{Procurement of raw ingredients}

Different raw materials that are needed for the preparation of Red yeast rice such as Rice, salt, etc. were purchased from the local market. The culture of Monascus purpureus was procured from Microbial Type Culture Collection, Chandigarh (MTCC) (Table 1-3).

\section{Standardization of Procedure for Preparation of Red Yeast Rice}

Red Yeast Rice is produced by Solid state fermentation of white non sticky rice with Monascus purpureus. The Monascus purpureus culture is obtained from Microbial Type Culture Collection, Chandigarh (MTCC). To get culture in the vegetative phase the spores were streaked or poured onto sterilized petriplates of PDA (Potato Dextrose Agar). Which were then kept for incubation at $28^{\circ} \mathrm{C}$ for 5 to 7 days. The Standard culture is obtained from above Mother culture which was then stored under aseptic conditions and Working culture was used for further investigation and studies in the research.

\section{Revival of Monascus purpureus Spores}

\section{Solid State Fermentation}

Rice variety that is white and non-sticky after cooking was used in this study. The SSF was performed by following the method explained by scientist (Chairote et al., 2007) with some changes. Rice was soaked in water overnight, after that $50 \mathrm{~g}$ of rice were placed in a 250 mlErlenmeyer flask and autoclaved at $121^{\circ} \mathrm{C}$ for 15 minutes. The moisture content of each rice variety was adjusted to $60 \%(\mathrm{w} / \mathrm{w})$ on a wet basis. After cooling, $2.5 \%$ of the liquid fungal inoculum was added and the inoculated flasks were incubated at $30^{\circ} \mathrm{C}$ in the darkness. After 14days, the fermented rice was collected and observed for color pigment development and this pigmented rice was dried at $60^{\circ} \mathrm{C}$ for 4 to 6 hours. In this study three replications were made for rice variety.

\section{Procedure for preparation of Red Yeast Rice}

Stepwise production of Red Yeast Rice is carried out by firstly immersion of rice in water for 6 hours following by steaming for $20 \mathrm{~min}$. After that the cooked rice was cooled, from that accurately, $50 \mathrm{~g}$ of steam rice was transferred in $250 \mathrm{ml}$ cotton Stoppered Erlenmeyer flask and sterilized at $15 \mathrm{psi}$ pressure and $121^{\circ} \mathrm{C}$ temperature for $15 \mathrm{~min}$. One week old pure and precultured Monascus purpureus was used as inoculums at $2.5 \%$ weight basis. The inoculated rice was incubated at $30^{\circ} \mathrm{C}$ for $14-16$ days with constant observations to check the pure 
growth conditions. The end-product was dried in the oven at temperature not exceeding $65^{\circ} \mathrm{C}$ for 4 to 6hours to obtain dried red yeast rice. The dried RYR is then powdered using domestic blender.

\section{Exploration of RYR in Ice-cream}

\section{Exploration of RYR in Sweetened Milk}

Colored sweetened milk is available in market with different colors like Yellow (Kesar or Badam), Pink (Strawberry or Rose), Chocolate, etc. Therefore, in the Studies of exploration of RYR powder as a colorant colored sweetened milk was chosen as one of the products as it provides great eye appeal and is also a natural colorant, concentration of the powder added is kept at $0.5 \%, 1.0 \%$ and $1.5 \%$ of the total milk volume.

\section{Results and Discussion}

\section{Physico-chemical properties of selected rice variety}

The physical characteristics of Rice play a very important role in development of processing technology. Data from Table 4 showed that the weight of 1000 grains were $18.66 \mathrm{gm}$, whereas length, width, thickness of flaxseed was $5.41 \mathrm{~mm}, 2.61 \mathrm{~mm}$, and $1.83 \mathrm{~mm}$ respectively. The shape and color were observed visually, the shape of Rice was found to be slender and color was white.

\section{Chemical composition of rice}

From Table 5 it can be seen that the moisture content in Rice was 9.2 percent and carbohydrate content was high and found to be 74.8 percent. The fat content was low at 0.9 percent and protein content was moderate in concentration i.e. 8.4 percent. Ash content of Rice was found to be 0.84 percent.

\section{Effect of cooking on chemical composition of rice}

From Table 6 we can see that the nutritional composition of raw and cooked rice varies greatly and found out as Moisture content of cooked rice as increased to 64.04 percent, whereas carbohydrates, fat, and proteins are decreased to 27.8 percent, 0.45 percent, and 2.76 percent respectively. The ash content of cooked rice is negligible at 0.3 percent.

\section{Mineral composition of rice}

The concentration of these minerals was recorded to be $80.54,350.40$, and 140.65 $(\mathrm{mg} / 1000 \mathrm{~g})$ respectively. The concentration of Calcium, Phosphorus, and Magnesium were much higher than the other inorganic minerals.

\section{Exploration of red yeast rice powder as a colorant in ice-cream}

The RYR powder concentration in samples is kept at blank for T0 sample, for T1 the powder is added at 1.5 percent, for $\mathrm{T} 2$ it was 1.0 percent and for T3 it was kept at 0.5 percent. The color added in Ice-cream was stable for up to 45 days in frozen conditions with no visual fading or discoloration. Data given in Table 8 revealed that the overall acceptability score recorded for sample T2 was found higher (8.0) followed by T3 (7.5) than other samples. The acceptability of samples varies as the ingredient variation are made.

The overall acceptability among samples was significantly varied statistically. The color and appearance serve as important parameters for the acceptance of food samples. The highest score for color of complementary food was recorded for sample T2 (7.6). Whereas, the lowest score received for control sample (7.0). There was a significant 
difference between the samples in context to color.

The maximum score for flavor attribute was received by sample $\mathrm{T} 2$ (7.8). While least score was noted in case of sample T1 (6.5). The texture of Ice-cream in table 7 showed that the formulation $\mathrm{T} 2$ got the highest value for taste (8.0) against T1 (7.0). There was a significant difference among the samples in context to all the sensory parameters. Overall, by considering the different sensory attributes, the formulation $\mathrm{T} 2$ was found to be superior to the other samples (Fig. 1-3).

Table.1 Standardized recipe for preparation of red yeast rice powder

\begin{tabular}{|c|c|}
\hline Material & Quantity \\
\hline Rice & $100 \mathrm{gm}$ \\
Salt & $0.86 \mathrm{gm}$ \\
Water & $200 \mathrm{ml}$ \\
\hline
\end{tabular}

Table.2 Recipe for preparation of ice cream

\begin{tabular}{|c|c|}
\hline Ingredients Required & Quantity \\
\hline White Sugar & $100 \mathrm{gm}$ \\
Whipping Cream & $100 \mathrm{gm}$ \\
Milk & $1000 \mathrm{ml}$ \\
CMC Powder & $2 \mathrm{gm}$ \\
GMS Powder & $2.5 \mathrm{gm}$ \\
Vanilla Extract & $5 \mathrm{ml}$ \\
\hline
\end{tabular}

Table.3 Recipe for sweetened milk preparation

\begin{tabular}{|c|c|}
\hline Ingredients Required & Quantity \\
\hline Cold milk & $200 \mathrm{ml}$ \\
Sugar & $100 \mathrm{gm}$ \\
Red Yeast Rice powder & As per formulation \\
Chilled water & $100 \mathrm{ml}$ \\
\hline
\end{tabular}

Table.4 Physical properties of rice

\begin{tabular}{|c|c|}
\hline Physical Parameters & Observation \\
\hline Colour & White \\
Shape & Slender \\
Length $(\mathbf{m m})$ & 5.41 \\
Width $(\mathbf{m m})$ & 2.61 \\
Thickness $(\mathbf{m m})$ & 1.83 \\
Wt. of 1000 seeds $(\mathbf{g})$ & 18.36 \\
Angle of Repose (Degree) & 37.1 \\
Density $(\mathbf{g} / \mathbf{m l})$ & 1.42 \\
\hline
\end{tabular}


Table.5 Chemical properties of rice

\begin{tabular}{|c|c|}
\hline Chemical Parameters & Observation (\%) \\
\hline Moisture (\%) & 9.2 \\
Crude Fat (\%) & 0.9 \\
Total Carbohydrates (\%) & 74.8 \\
Total Protein (\%) & 8.4 \\
Ash (\%) & 0.84 \\
\hline
\end{tabular}

Table.6 Chemical composition of rice after cooking

\begin{tabular}{|c|c|}
\hline Chemical Parameters & Observation (\%) \\
\hline Moisture (\%) & 64.04 \\
Crude Fat (\%) & 0.45 \\
Total Carbohydrates (\%) & 27.8 \\
Total Protein (\%) & 2.76 \\
Ash (\%) & 0.3 \\
\hline
\end{tabular}

Table.7 Mineral content in Rice

\begin{tabular}{|c|c|}
\hline Minerals & Average value(mg/1000g) \\
\hline Calcium & 80.54 \\
Phosphorus & 350.40 \\
Magnesium & 140.65 \\
\hline
\end{tabular}

Table.8 Sensory evaluation of ice-cream

\begin{tabular}{|c|c|c|c|c|c|}
\hline \multirow{2}{*}{ Treatments } & \multicolumn{3}{|c|}{ Sensory Characteristics } & \\
\cline { 2 - 5 } & $\begin{array}{c}\text { Colour } \boldsymbol{8} \\
\text { Appearance }\end{array}$ & Flavor & Texture & Taste & $\begin{array}{c}\text { Overall } \\
\text { Acceptability }\end{array}$ \\
\hline T0 & 7.000 & 7.500 & 7.500 & 7.500 & 7.400 \\
\hline T1 & 7.500 & 6.500 & 7.000 & 7.000 & 7.200 \\
\hline T2 & $\mathbf{7 . 6 0 0}$ & $\mathbf{7 . 8 0 0}$ & $\mathbf{8 . 0 0 0}$ & $\mathbf{8 . 5 0 0}$ & $\mathbf{8 . 0 0 0}$ \\
\hline T3 & 7.500 & 6.500 & 7.500 & 8.000 & 7.500 \\
\hline C.D. & 0.165 & 0.182 & 0.156 & 0.196 & 0.143 \\
\hline SE & 0.056 & 0.061 & 0.052 & 0.066 & 0.048 \\
\hline
\end{tabular}

Table.9 Sensory evaluation of colored sweetened milk

\begin{tabular}{|c|c|c|c|c|c|}
\hline \multirow{2}{*}{ Treatments } & & \multicolumn{3}{|c|}{ Sensory Characteristics } & \\
\cline { 2 - 5 } & Colour \& Appearance & Flavor & Texture & Taste & Overall Acceptability \\
\hline T0 & 7.000 & 7.700 & 7.500 & 7.800 & 7.500 \\
\hline T1 & 7.500 & 7.500 & 7.000 & 7.000 & 7.500 \\
\hline T2 & $\mathbf{8 . 6 0 0}$ & $\mathbf{7 . 8 0 0}$ & $\mathbf{8 . 0 0 0}$ & $\mathbf{8 . 5 0 0}$ & $\mathbf{8 . 2 5 0}$ \\
\hline T3 & 7.500 & 7.500 & 7.500 & 7.600 & 7.550 \\
\hline C.D. & 0.167 & 0.172 & 0.205 & 0.182 & 0.196 \\
\hline SE & 0.056 & 0.058 & 0.069 & 0.061 & 0.066 \\
\hline
\end{tabular}


Table.10 Ice-cream added with RYR powder

\begin{tabular}{|c|c|}
\hline Nutrient & Quantity (per $\mathbf{1 0 0} \mathbf{~ m l})$ \\
\hline Energy & $194 \mathrm{kcal}$ \\
\hline Carbohydrates & $18 \mathrm{gm}$ \\
\hline Proteins & $4 \mathrm{gm}$ \\
\hline Fat & $12 \mathrm{gm}$ \\
\hline Calcium & $110 \mathrm{mg}$ \\
\hline
\end{tabular}

Table.11 Sweetened Milk added with RYR Powder

\begin{tabular}{|c|c|}
\hline Nutrient & Quantity $(\mathbf{p e r} \mathbf{1 0 0} \mathbf{~ m l})$ \\
\hline Energy & $89 \mathrm{kcal}$ \\
\hline Carbohydrates & $12.0 \mathrm{gm}$ \\
\hline Proteins & $3.0 \mathrm{gm}$ \\
\hline Fat & $3.1 \mathrm{gm}$ \\
\hline Calcium & $120 \mathrm{mg}$ \\
\hline
\end{tabular}

Table.12 Microbial analysis of Red yeast rice powder

\begin{tabular}{|c|c|}
\hline Parameter & Observation \\
\hline Total Plate Count $(\mathrm{CFU} / \mathrm{mL})$ & ND \\
\hline Yeast and Mold Count $(\mathrm{CFU} / \mathrm{mL})$ & $\mathbf{6 . 4} \times \mathbf{x 1 0}^{\mathbf{8}}$ \\
\hline Coliform Count $(\mathrm{MPN} / \mathrm{mL})$ & ND \\
\hline
\end{tabular}

Fig.1 Red yeast rice powder

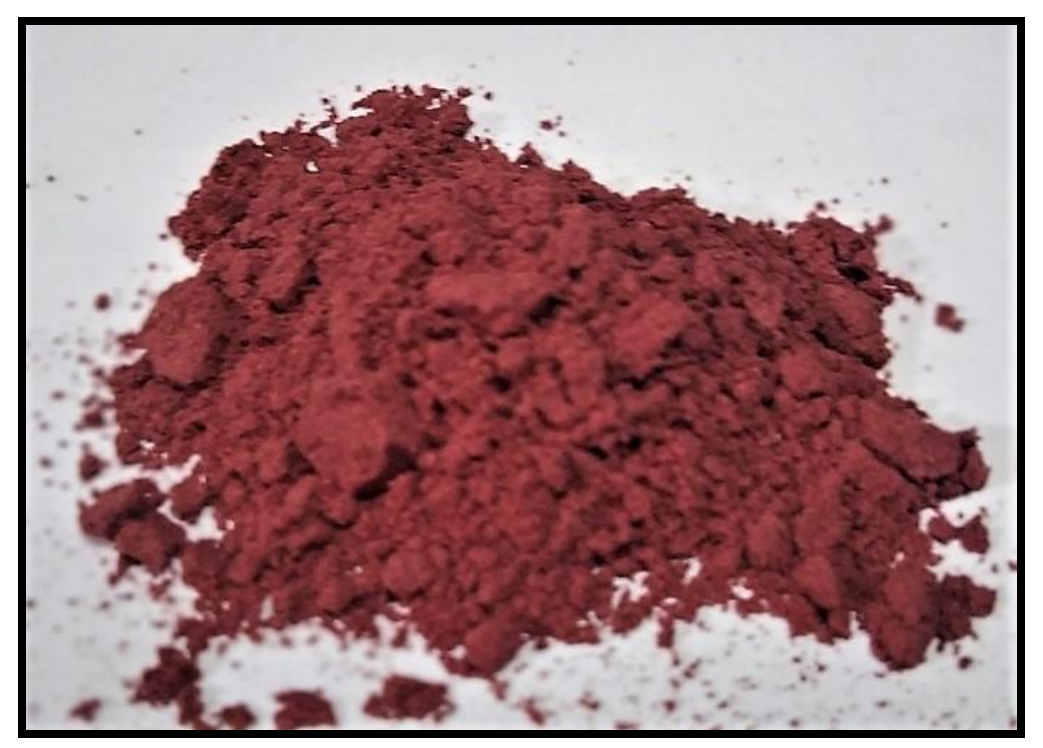


Fig.2

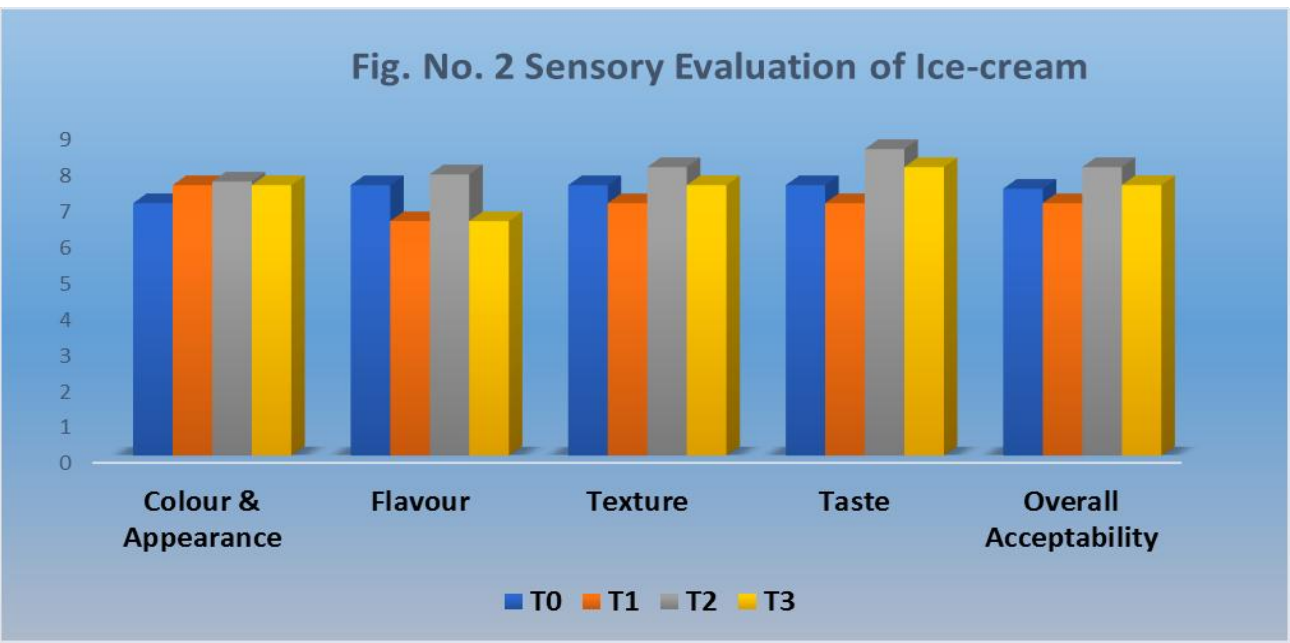

Fig.3

Fig. No. 3 Sensory Evaluation of Colored Sweetened milk

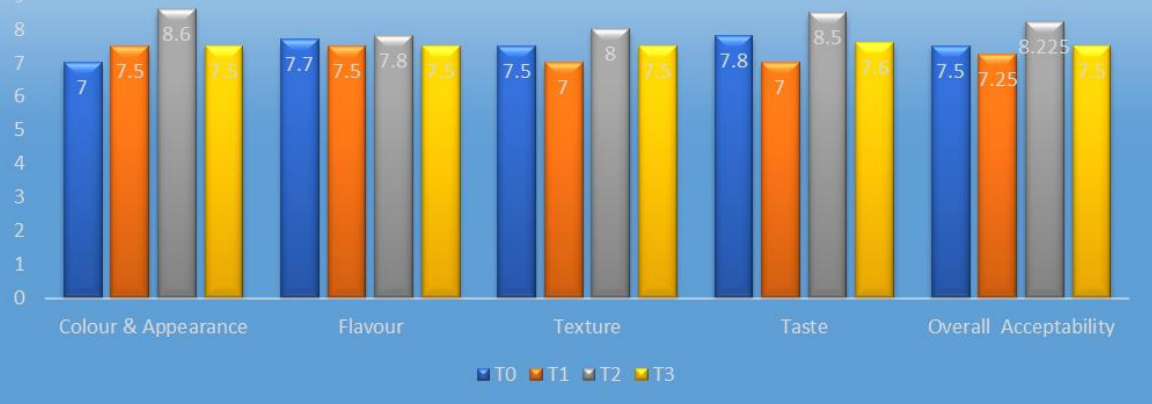

Flow sheet.1 Revival of Monascus purpureus spores

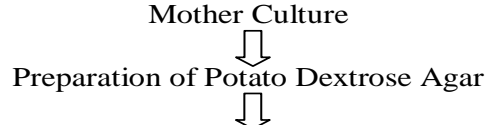

Sterilization of PD Agar in autoclave at $121^{\circ} \mathrm{C}$ for 30 minutes

Transfer of PD Agar into pre-sterilized petri plates

Allow agar to solidify in petri plates 凸

Transfer a loopful of culture from mother culture tube into solidified cooled petri plates ת

Keep inoculated petri plates in incubator for 5 to 7 days at $28^{\circ} \mathrm{C}$ 凹

Observe for the red colored cottony growth of Monascus purpureus 
Flow Sheet.2 Production of Red Yeast Rice Powder (RYRP)

Take $100 \mathrm{gm}$ of rice in $1000 \mathrm{ml}$ conical flask

Wash 3 to 4 times with ample quantity of water

$\square$

Prepare $200 \mathrm{ml}$ of 0.86 percent saline solution

(For this dissolve $0.086 \mathrm{gm} \mathrm{NaCl}$ in $10 \mathrm{ml}$ of water and adjust $\mathrm{pH} 6.7$ with $\mathrm{HCl}$ )

Transfer the solution into conical flask and shake thoroughly

Place a cotton topper on the neck of conical flask

凸

Sterilize it in autoclave at $121^{\circ} \mathrm{C}$ for 25 minutes

(Let the flask cool till it reaches the normal temperature)

П

Check Rice grains if they are completely cooked

$\square$

To this cooked rice add Monascus purpureus culture at 2 percent

$\square$

Incubate in Incubator at $28^{\circ} \mathrm{C}$ for $10-14$ days

Ø

Check for color pigment production intermittently

П

Transfer the fermented rice from conical flask to the clean and sterilized petri plate and spread evenly

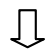

Dry it in oven at $55^{\circ} \mathrm{C}$ for 5-6 hours or until moisture content is reduced $10 \%$

$\prod$

Grinding into powder with uniform particle size and packing in Aluminum foil with LDPE

乙)

Store it in cool and dry place.

Flow Sheet.3 Preparation of ice cream

Add Milk, CMC powder and GMS powder and stir continuously in bowl

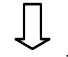

Take Half of the mixture quantity and start heating on low flame, add sugar and stir occasionally. Now allow mixture to reduce to half or till milk consistency is thick.

Add fresh cream, vanilla essence and powdered RYR and after even mixing is done turn off the flame and transfer the contents into a setting aluminum container with aluminum foil on top and freeze for 6 hours.

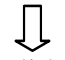

Once the ice cream is set or semi solid blend it in blender to incorporate air

П

Transfer again to the container and freeze it for 10 hours

П

Vanilla Ice cream with RYR powder incorporation is ready, serve chilled. 
Flow sheet.4 Preparation of colored sweetened milk

Add sugar to Water in heavy bottom flask and start heating and stir to dissolve sugar.<smiles>[C]1[C+]=CC=C1</smiles>

Boil it for 5 minutes on medium flame and add RYR powder according to the recipe to it.<smiles>[CH]</smiles>

Let the syrup become slightly thick liquid.

ח

Cool down syrup and store it in bottle.

凸

Boil milk and allow it cool for some time.

Add milk to syrup in 3:1 proportion.

ఐ

Stir well and serve chilled.

Exploration of red yeast rice powder as a colorant in sweetened milk

The RYR powder concentration in sample is kept at blank for T0 sample, for T1 the powder is added at 1.5 percent, for $\mathrm{T} 2$ it was 1.0 percent and for T3 it was kept at 0.5 percent. The color added was stable for up to 15 days in refrigerated conditions with no visual fading or discoloration in the product color. Data given in Table 9 revealed that the overall acceptability score recorded for sample T2 was found higher (8.25) followed by T3 (7.55) than other samples. The appeal and acceptability of samples depends on variation in the ingredient composition. The overall acceptability among samples was significantly varied statistically. The color and appearance serve as important parameters for the acceptance of food samples. The highest score for color of complementary food was recorded for sample T2 (8.6). Whereas, the lowest score received for the control sample (7.0). There was a significant difference between the samples in context to color. The maximum score for flavor attribute was received by sample T2 (7.8). While least score was noted in case of sample T1 (6.5). The texture of the product from table 9 showed that the formulation $\mathrm{T} 2$ got the highest value for taste (8.25) against T1 (7.50). There was a significant difference among the samples in context to all the sensory parameters. Overall, by considering the different sensory attributes, the formulation $\mathrm{T} 2$ was found to be superior to the other samples.

\section{Nutritional content of ice-cream added with RYR powder}

This is near to neutral $\mathrm{pH}$ product which is a rich source of fat, milk proteins, and Sugars. Color plays an important role in acceptability of ice-cream. Therefore, we chose it to be added with RYR powder which will give red color and thereby induce acceptability. A Typical nutrient composition or Ice-cream is given below. It can be defined as a soft, sweet frozen food made by milk and cream which is flavored with vanilla, mango, etc. Nutritional information for Ice cream is given in Table 10 .

\section{Nutritional content of sweetened milk added with RYR powder}

Sweetened flavored and colored milk are available in market to increase the visual appearance and to enhance the color RYR 
powder at a concentration of $1 \%$ is added to the milk. It is a sweetened dairy drink made with milk, sugar, flavor, and coloring. It is commonly marketed as a pasteurized and chilled product. Nutritional information for sweetened colored milk is given in Table 11.

\section{Microbial analysis of red yeast rice powder}

The growth of harmful and unwanted microorganisms will spoil the prepared product and may lead to different types of food borne diseases which can affect the human health and body. Therefore, microbial analysis of the prepared powder is mandatory to prevent the product from spoilage and also maintain the safety. The data related to microbiological analysis of RYR powder is given in Table 12.

In the present work, the count of beneficial mold was detected as $6.4 \times 10^{8} \mathrm{CFU} / \mathrm{ml}$ and bacterial count was not detected in a powder. This count was in suitable range as observed in similar food products. On the other hand, coli-form measure was also carried out. Coliform were not detected in the prepared food sample, which showed that the prepared probiotic beverage was free of any pathogenic and harmful microbes and safe for consumption.

On the basis of findings, it was concluded that the products prepared by using Red Yeast Rice powder as a colorant could be considered as the best from both nutritional and sensory point of view. The Red Yeast Rice powder at the ratio of 1.0 percent was good in terms of color, texture and appearance. The prepared Red yeast Rice powder was stable at room temperature for 90 days when properly packed in suitable packaging material. The fact that it is cheap than the ones which are being sold in market. Hence, it can be concluded that Red Yeast Rice powder is economically feasible to explore on a commercial scale.

\section{References}

Burke, F.M. (2015): "Red yeast rice for the treatment of dyslipidemia". Current Atherosclerosis Report; 17(4): 495498.

Chen X. P., (1987): "Research status on prescriptions for 52 diseases". J. Traditional Medicines; 5(1), 61-63.

DeFelice, S.L. (1995): "The nutraceutical revolution: its impact on food industry R\&D". Trends in Food Science and Technology; 6 (1), 59-61.

Endo A., and Monacolin K. (1989): “A new hypocholestolemic agent that specifically inhibits 3-hydroxy-3methulglutaryl coenzyme A reductase". Journal of Antibiotics; 33(3):334-4

Fink-Grammels J., and Leistner L. (2008): "Biogische wirking von Monascus Purpureus". Food Microbiology; 126(2): 20-23.

Gulshan Mahajan, Vivek Kumar, and Bhagirath S. Chauhan (2017) Chapter 3, "Rice Production in India"; 54-88.

Hajjaj H., Klaebe A., Goma G., Blanc P. J., Barbier E., Francois J., (2000): "Medium- chain fatty acids affect citrinin production in the filamentous fungus Monascus ruber". Applied Environmental Microbiology; 66(3): 1105- 20.

Hesseltine C. W. (1979): "Solid-state fermentations an overview". International. Biodeteriorator; 23(1): 79-89.

Ma, J. (2000): "Constituents of red yeast rice, a traditional Chinese food and medicine". Journal on Agricultural Food Chemistry; 48(1), 5220-5225.

Patel, S. (2016): "Functional food red yeast rice (RYR) for metabolic syndrome amelioration: a review on pros and 
cons". World Journal Microbiology and Biotechnology; 32(1), 2035-2042.

Tieghem V., (1884): "Monascus, genre nouveau de l'ordre des Ascomycetes". Bulletin de la Societe Botanique de France; 31(1): 226-231.

Went F. A. and F. C., (1895): "Monascus purpureus. le champignon de l'angquac une nouvelle the lebolee". Annales des Sciences Naturalles Botanics. Biodiversity; 8(1), 1-17.
Woranan N.and Prasad M.(2015): “ Increasing the Value of Rice by Transformation into Red Yeast Rice". Journal of Science and Technology; 34(5): 504-512.

Zhang Z., Ali Z., Khan S.I., and Khan I.A., (2016): "Cytotoxic monacolins from red yeast rice, a Chinese medicine and food”. Food Chemistry. 202, 262-268.

\section{How to cite this article:}

Toshniwal, D. D., H. W. Deshpande, S. D. Katke and Sawate, A. R. 2020. Studies on Exploration of Red Yeast Rice Powder as a Colorant in Ice-Cream and Sweetened Milk. Int.J.Curr.Microbiol.App.Sci. 9(09): 1641-1652. doi: https://doi.org/10.20546/ijcmas.2020.909.204 